\title{
DELIMITAÇÃO E CARACTERIZAÇÃO MICROMORFOLÓGICA DE ESPÉCIES DE MICROPHOLIS (GRISEB.) PIERRE (SAPOTACEAE) DA BAHIA
}

\author{
Jamile de Jesus Peixoto ${ }^{1}$ e Cláudia Elena Carneiro ${ }^{2}$ \\ 1. Bolsista PIBIC/CNPq, Graduanda em Ciências Biológicas - Bacharelado, Universidade Estadual de Feira de \\ Santana, e-mail: jamilipeixoto08@ hotmail.com \\ 2. Orientadora, Departamento de Ciências Biológicas (DCB), Laboratório de Micromorfologia Vegetal (LAMIV), \\ Universidade Estadual de Feira de Santana, e-mail: carneiro@uefs.br
}

PALAVRAS-CHAVE: Anatomia; Descrição; Taxonomia.

\section{INTRODUÇÃO}

A Bahia apresenta um território extenso, abrangendo 564.732,624 $\mathrm{Km}^{2}$ do Nordeste (IBGE, 2015). Neste estado há uma elevada diversidade vegetal onde a família Sapotaceae está incluída. Esta família é caracterizada por árvores ou arbustos de folhas alternas ou raramente opostas ou verticiladas e sem estípulas e também pela presença de tricomas malpiguiáceo. Possuem frutos comestíveis, a exemplo do sapoti, que pode ser comercializado para consumo ou pode fazer parte da dieta de animais. A família também possui importância econômica, com a utilização da madeira e do látex na produção de artefatos e goma de mascar, respectivamente (Pennington, 1990). Sapotaceae possui 12 gêneros citados para o Brasil e 232 espécies; para a Bahia são citadas 77 espécies distribuídas em 11 gêneros (Carneiro et al., 2016). Micropholis é o terceiro maior gênero desta família e é alvo do presente trabalho. Para a Bahia são citadas sete espécies, sendo importante destacar que quatro destas encontram-se na Lista Vermelha da Flora Ameaçada, tendo Micropholis emarginata T.D. Penn em situação de risco elevado de extinção na natureza (CNCFlora, Miguel d'Avila de Moraes, 2011). Sabendo-se deste dado para as espécies, na importância que a família e o gênero possuem na utilização da madeira desta e de outras espécies, a presente pesquisa objetivou levantar e descrever a micromorfologia das folhas das espécies de Micropholis que ocorrem na Bahia, visando contribuir para a delimitação taxonômica destas, já que são muito escassos estudos sobre o gênero e também auxiliar no levantamento de espécies que mesmo tendo risco de ameaça ainda têm ocorrência no estado.

\section{MATERIAL E MÉTODOS}

O material utilizado foram duplicatas depositadas no Herbário da Universidade Estadual de Feira de Santana (HUEFS) de coletas feitas na Bahia anteriormente. Foi feito um levantamento prévio das espécies ocorrentes na Bahia a partir do site Lista de Espécies da Flora do Brasil, ao qual citam as espécies que são de ocorrência no estado. O material utilizado já estava devidamente identificado no herbário pelo seu determinante (ou especialistas do grupo) e dados de coleta. Para o processamento e a análise do material foram utilizadas as técnicas usuais em anatomia vegetal, conforme o manual de Kraus e Arduin (1997). Folhas inteiras foram reidratadas com água destilada e glicerina a $50 \%$ e estendidas em Hidróxido de Potássio a 20\%. Cortes transversais à mão livre foram realizados no ápice, bordo, base e região da nervura central da lâmina foliar, e no pecíolo, sendo clarificados com Hipoclorito de Sódio a $10 \%$ e corados com Azul de Astra a 1\% e Safranina a 1\%, na proporção de 9:1 (v/v). Para a obtenção da epiderme foi utilizado o método de Jeffrey (solução de Ácido Crômico a $10 \%$ e Ácido Nítrico a 10\%, na proporção de 1:1), e as amostras foram coradas com Safranina a $1 \%$. Como alternativa para obtenção da epiderme, foi feita também, a inserção do material 
em Hipoclorito de Sódio a $10 \%$ até clarificação total das folhas e posteriormente extração da epiderme. Para obtenção de dados histoquímicos, as amostras foram submetidas aos seguintes reagentes: Lugol, Sudan IV, Cloreto Férrico e Floroglucina, os quais identificam amido, lipídios, compostos fenólicos e lignina, respectivamente. Todas as amostras foram montadas entre lâmina e lamínula com glicerina a $50 \%$ e vedadas com esmalte incolor. As análises foram realizadas em microscópio de luz e as imagens obtidas em Fotomicroscópio.

\section{RESULTADOS E DISCUSSÃO}

Foram identificadas e descritas sete espécies para o estado da Bahia: Micropholis compta Pierre, M. crassipedicellata (Mart. \& Eichler ex. Miq) Pierre, $M$. emarginata T.D. Penn, M. gardneriana (A.DC.) Pierre, M. gnaphaloclados (Mart.) Pierre, M. guyanensis (A.DC.) Pierre e M. venulosa (Mart. \& Eichler) Pierre. De acordo com o estudo, todas as espécies possuem características anatômicas em comum, tais como a presença de epiderme unisseriada e estômatos localizados somente na face abaxial. Em vista frontal, as células da epiderme variam no formato do contorno da parede anticlinal de pouco sinuoso a muito sinuoso nas espécies, e os estômatos encontrados são do tipo anomocítico e anisocítico. O mesofilo se mostrou dorsiventral em todas as espécies e com parênquima paliçádico e lacunoso variando em número de camadas e proporção na área. No bordo, a cutícula se apresenta formando flange para algumas espécies como em $M$. crassipedicellata, M. gardneriana e M. guyanensis. $\mathrm{O}$ feixe vascular é do tipo colateral com floema envolvendo o xilema e estes circundados por um cinturão de esclerênquima. A presença de laticíferos e cristais, que são característicos da família, foi encontrada também em todas as espécies (Figura 1). Alguns destes dados corroboram com Metcalfe \& Chalk (1957). Apesar de alguns caracteres serem semelhantes houve diferenciação na anatomia das espécies. A cutícula de $M$. emarginata e $M$. gnaphaloclados se mostrou muito espessa provavelmente se caracterizando como adaptação ao ambiente de Cerrado (Mucugê), onde ambos os indivíduos foram coletados. O esclerênquima que circunda o feixe vascular principal em $M$. venulosa e $M$. compta formam fileiras que se estendem até a região subepidérmica adaxial. M. gardneriana possui uma arranjo diferente na distribuição dos parênquimas no mesofilo onde o paliçádico ocupa $1 / 3$ da área comparado ao lacunoso. $M$. crassipedicellta tem a presença de laticíferos associada aos feixes vasculares, aos quais estes intercalam o parênquima do mesofilo. Para $M$. guyanensis a diferença na micromorfologia está atrelada às circunvoluções que o feixe vascular em formação vai formando quando "englobados" pelo feixe principal. Os estudos de Valente et al. (2013) descrevem a morfologia externa de algumas espécies de Micropholis. Estes estudos foram realizados para espécies $M$. venulosa e $M$. gnaphalocldos do litoral paraense e cita as principais diferenças entre elas. As descrições micromorfológicas, neste caso, são complementares à morfologia e ambas serão aplicadas à delimitação taxonômica do grupo. Desta forma, os dados encontrados poderão subsidiar estudos que tratem da diferenciação das espécies. As espécies apresentaram amido no parênquima em torno do feixe vascular e no parênquima paliçádico do mesofilo. Os compostos fenólicos foram observados em todo o parênquima de preenchimento e no mesofilo; a lignina no xilema; e lipídios principalmente na cutícula. A identificação destes compostos pode auxiliar a bioprospecção já que alguns destes compostos podem ter importância nesta aplicação, além de auxiliar na taxonomia. 

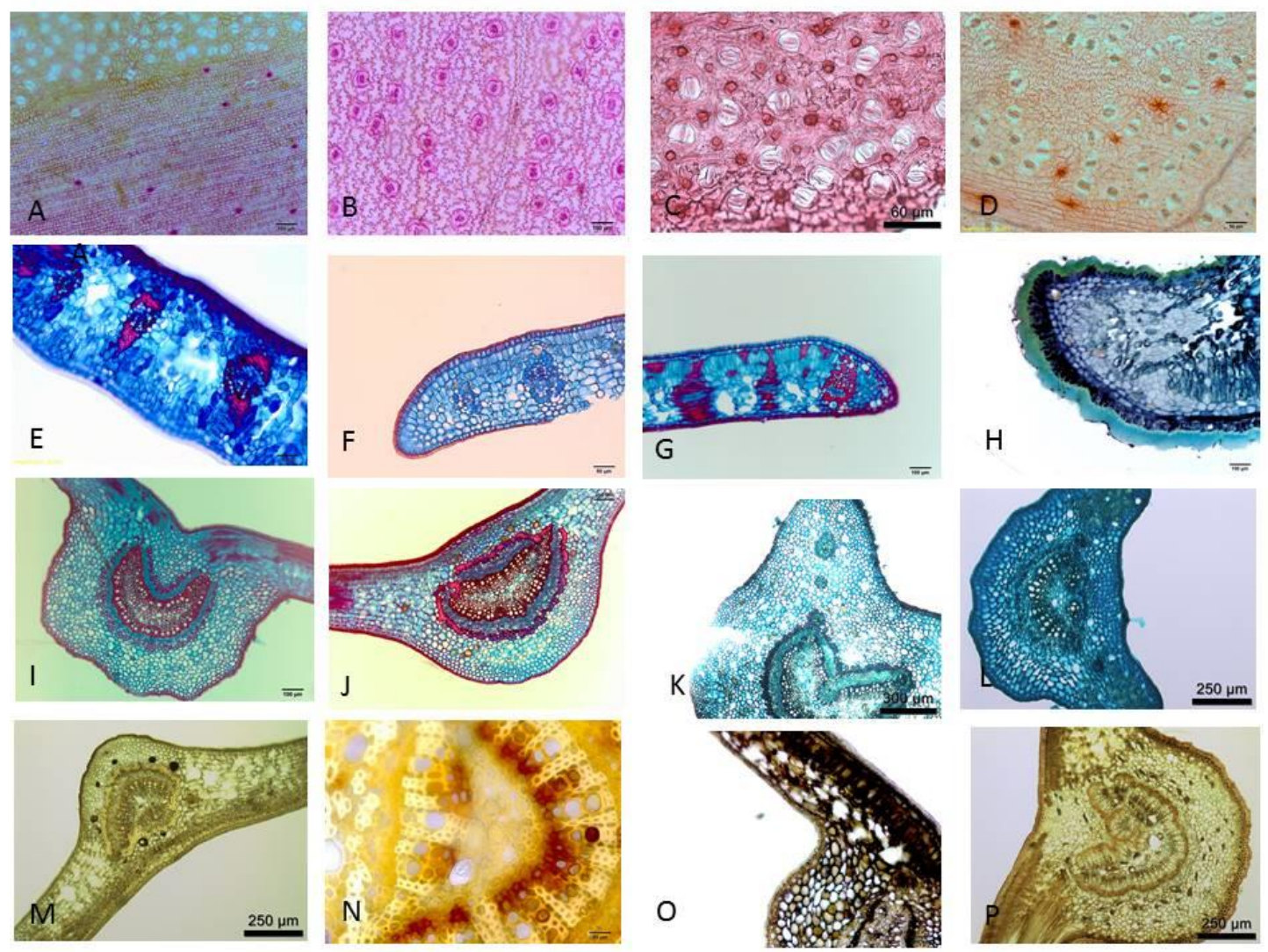

Figura 1. Imagens da anatomia das espécies citadas. A à D. Vista frontal da epiderme abaxial, A. Micropholis crassipedicellata (Mart. \& Eichler ex. Miq) Pierre, B. Micropholis compta Pierre, C. Micropholis emarginata T.D. Penn e D. Micropholis gnaphaloclados (Mart.) Pierre . E à P. Secção transversal da lâmina foliar, E. Região do mesofilo de Micropholis gnaphaloclados (Mart.) Pierre, F. Região do bordo de Micropholis crassipedicellata (Mart. \& Eichler ex. Miq) Pierre, G. Região do bordo de Micropholis gardneriana (A.DC.) Pierre, H. Bordo em Micropholis emarginata T.D. Penn, I. Região da nervura central de Micropholis gardneriana (A.DC.) Pierre, J. Mesma região em Micropholis crassipedicellata (Mart. \& Eichler ex. Miq) Pierre, K. Pecíolo de Micropholis guyanensis (A.DC.) Pierre, L. Pecíolo de Micropholis venulosa (Mart. \& Eichler) Pierre. M à P. Reações dos testes histoquímicos na região da nervura central em M. Micropholis crassipedicellata (Mart. \& Eichler ex. Miq) Pierre com Lugol, N. Micropholis compta Pierre com Floroglucina, O. Micropholis gardneriana (A.DC.) Pierre com Cloreto Férrico e P. Micropholis guvanensis (A.DC.) Pierre com Sudan IV.

\section{CONCLUSÃO}

Os dados obtidos podem contribuir para delimitação taxonômica das espécies de Micropholis para a Bahia, onde estas espécies podem ser diferenciadas pelo arranjo da distribuição do parênquima paliçádico e lacunoso no mesofilo, pela forma dos sistemas vasculares, conformação do feixe de esclerênquima que envolve este e também pelo tipo de estômato. $\mathrm{O}$ espessamento da cutícula e a presença de esclerênquima de sustentação no mesofilo foram identificadores de algumas espécies, porém esta pode ser uma característica relacionada ao ambiente de coleta destas espécies.

\section{REFERÊNCIAS}

CARNEIRO, C.E., ALVES-ARAUJO, A., ALMEIDA JR., E.B., TERRA-ARAUJO, M.H. 2016. [online] Sapotaceae. In Flora do Brasil 2020 em construção. Jardim Botânico do Rio de Janeiro. Homepage: http://floradobrasil.jbrj.gov.br/reflora/floradobrasil/FB217.

CNCFlora. 2016 [online]. Micropholis emarginata in Lista Vermelha da Flora Brasileira, versão 2016.1 Centro Nacional de Conservação da Flora. Homepage: http://cncflora.jbrj.gov.br/portal/pt-br/profile/Micropholis emarginata.

IBGE. 2015 [online]. Homepage: http://www.ibge.gov.br. 
KRAUS, J.E.; ARDUIN, M. 1997. Manual básico de métodos em Morfologia Vegetal. Editora EDUR, Rio de Janeiro, 198p.

METCALFE C.R. \& CHALK L. 1957. Anatomy of the dicotyledons. Leaves, stem, and wood in relation to taxonomy with notes on economic uses. Oxford at the Clarendon Press.

PENNINGTON, T.D. 1990. Sapotaceae. Flora Neotropica, v.52. The New York

Botanical Gardens, 770p.

VALENTE, D.M., SOUSA J.S., BASTOS M.N.C. 2013. Estudo taxonômico de Sapotaceae Juss. do litoral Paraense. Acta Amazônica 43(2):161-168. 